\title{
Neonatal thymectomy affects follicle populations before the onset of autoimmune oophoritis in B6A mice*
}

\author{
M. M. Kosiewicz and S. D. Michael \\ Department of Biological Sciences, State University of New York, Binghamton, NY 1390I, USA
}

\begin{abstract}
Summary. Using a variation on a standard follicle classification technique, 5 classes of follicles were quantified in serial sections of ovaries from intact mice and mice thymectomized on Day 3 at 5-day intervals from 5 to 40 days of age. Sera from these animals and from animals 60 days of age were analysed for the presence of anti-oocyte antibodies. Ovaries from intact animals 10 to 40 days of age were examined for the presence of antigen(s) using anti-oocyte antibody-positive sera from all ages of mice. There was a dramatic decrease in the primordial follicle population at 10 days of age in thymectomized mice and that population remained significantly lower until 40 days of age. The growing follicle population was also significantly lower at 20 days of age in thymectomized mice and remained lower through 40 days of age. Anti-oocyte antibodies were not detectable until 30 days of age and at that age reacted with oocytes from all follicle types including primordial. Ovarian antigens were present in similar patterns in ovaries from mice at all ages tested. We conclude that thymectomy has an earlier influence on the ovary than previously thought and this influence does not appear to involve the immune activity associated with autoimmune ovarian dysgenesis. This suggests that the effect of thymectomy on the ovary may be biphasic: (1) an early effect, possibly involving a disruption in the hypothalamic-pituitary-ovarian-thymic axis, that influences the primordial and growing follicle populations before 20 days of age; and (2) a later effect involving an immune imbalance first evident by $25-30$ days of age that ultimately results in the destruction of the ovary.
\end{abstract}

Keywords: neonatal thymectomy; mice; follicles; ovarian dysgenesis; autoimmunity

\section{Introduction}

Neonatal thymectomy induces premature sterility in several species of mammals (Lintern-Moore, 1977; Kojima \& Prehn, 1981; Healy et al., 1985). Nishizuka \& Sakakura (1969) reported a high incidence of ovarian dysgenesis in female mice thymectomized between 2 and 4 days of age. Subsequent studies determined that the age at which ovarian dysgenesis occurs after thymectomy varies with the strain of mice. In the B6A hybrid, ovarian dysgenesis is usually completed by 60 days of age. Characteristics of ovarian dysgenesis in B6A mice include: (1) rapid loss of oocytes; (2) increased follicular atresia; (3) total absence of corpora lutea; (4) decreased ovarian weight; and (5) infiltration of lymphocytes into the ovary. Other features which are associated with ovarian dysgenesis include: (1) delay in vaginal opening; (2) presence of circulating anti-oocyte antibodies; and (3) in prepubertal animals, lower concentrations of circulating luteinizing hormone (LH), follicle stimulating hormone (FSH) and growth hormone $(\mathrm{GH})$ (for review see Michael, 1983).

Taguchi et al. (1980) show that oophoritis, which is indicated by the presence of infiltration lymphocytes, is first found at about 25 days of age in B6A mice and appears to correlate with the

*Reprint requests to Dr S. D. Michael. 
initial appearance of circulating anti-oocyte antibodies. The anti-oocyte antibodies that result from thymectomy react specifically to antigens in the ooplasm of oocytes within growing follicles (Taguchi et al., 1980). A later study by the same group involving the quantification of follicles at various stages of development found a dramatic decrease in growing and primordial follicles at about 50 days of age. We have consistently found that ovarian dysgenesis occurs earlier in thymectomized animals in our laboratory (complete ovarian dysgenesis by 40 days of age compared to the 60 days of age reported by Miyake et al., 1987) and we have also noted other differences between the two laboratories. These differences include: (1) the presence of fewer small, growing follicles by 20 days of age in thymectomized mice (a non-quantitative evaluation); and (2) a different specificity of anti-oocyte antibodies in that sera from thymectomized mice react with oocytes from all follicle types (including primordial, growing and pre-Graafian follicles) not exclusively growing follicles. In the present study we determined the effect of thymectomy in altering the numbers of the five major follicle populations in mice before and during the onset of ovarian dysgenesis and attempted to identify a correlation between the presence of multi-reactive sera from thymectomized mice and changes within specific follicle populations.

\title{
Materials and Methods
}

\begin{abstract}
Animals. Female mice of the hybrid strain $(\mathrm{C} 57 \mathrm{BL} / 6 \mathrm{JCr} \times \mathrm{A} / \mathrm{J}) \mathrm{F}_{1}(\mathrm{~B} 6 \mathrm{~A})$ from our breeding colony were used for this study. Animals were maintained at room temperature on a $14 \mathrm{~h}$ light: $10 \mathrm{~h}$ dark schedule and had food and tap water available ad libitum. Females were isolated when visibly pregnant and births were recorded (Day 0) between 10:00 and 12:00 $\mathrm{h}$ daily. Animals were weaned at 24 days of age.
\end{abstract}

Surgery and sample collection. Thymectomy was performed at Day 3 of age (Tx-3) under ether anaesthesia via a suction pipette technique (Nishizuka \& Sakakura, 1971). Intact and thymectomized mice were killed by decapitation at 5-day intervals from 5 to $\mathbf{4 0}$ days of age. Sham thymectomy was performed as a control for surgical stress and these mice were killed at 10-day intervals from 10 to 40 days of age. Blood was collected from all animals mentioned above and also from 60-day-old female thymectomized mice and the plasma was frozen for future use in immunofluorescent studies. Both ovaries were removed at autopsy, weighed, fixed in Dietrich's solution for $48 \mathrm{~h}$, dehydrated, doubly embedded in nitrocellulose and paraffin wax, and then serially sectioned at $5 \mu \mathrm{m}$ thickness. Sections were stained with Weigert's haematoxylin and lightly counterstained with eosin Y.

Follicle analyses. Follicles from right and left ovaries were counted and the average number from the two ovaries were used for statistical analyses. Follicles were classified by a modification of the method of Pedersen \& Peters (1968) (see also Peters \& McNatty, 1980). This system is based on oocyte size, granulosa cell number in the largest follicular cross section, and follicular morphology (see Fig. 1). Primordial follicles were counted in every 10th section and the resultant number multiplied by 5 to determine the actual number per ovary the average diameter of a primordial oocyte is $8 \mu \mathrm{m}$ ). We found no significant differences between this procedure and the number found by counting follicles in every 2 nd section. All other classes of follicles were counted in every section with the nucleolus of the oocyte used as a marker. Oocyte size was determined by use of an ocular micrometer, calculated by taking the average of two diameters at right angles to each other. All follicles were counted unless the oocyte exhibited evidence of degeneration such as eosinophilic inclusions, meiotic resumption, nuclear clumping or oocyte atrophy.

All data are presented as mean \pm s.e.m. Data were analysed by Student's $t$ test or linear regression analysis. Differences were considered significant if $P<0.05$ unless otherwise indicated.

Immunofluorescence. The technique of indirect immunofluorescence was used to screen plasma from 10-, 20-, 30-, 40- and 60-day-old thymectomized female mice for the presence and specificity of anti-oocyte antibodies. For this purpose, ovaries from 10-, 20- and 30-day-old intact mice were frozen, sectioned at $6 \mu \mathrm{m}$ and fixed in acetone for $15 \mathrm{sec}$. The sections were incubated with $20 \mu$ diluted serum ( $\times 6$ dilution with PBS; pH 7.25 ) for 15 min at room temperature in a humidifed chamber, then washed in PBS for $15 \mathrm{~min}$. After washing, the sections were incubated with $20 \mu \mathrm{l}$ FITC-labelled goat anti-mouse IgG (Sigma Corporation, St Louis, MO, USA; diluted 1:16) for 30 min under the above conditions and washed again in PBS for $15 \mathrm{~min}$. Sections were mounted using a commercially prepared aqueous mounting medium (Biomeda Corporation, Foster City, CA, USA) and overlaid with a coverslip. Fluorescence was detected using an Olympus BHT epifluorescence microscope equipped with a 100-W mercury lamp, $490 \mathrm{~nm}$ FITC-exciter filter, $515 \mathrm{~nm}$ barrier filter and Fluorite objective lenses $(\times 20$ and $\times 40$ used for photography). Sections treated with plasma from intact mice of comparable age were used for controls. Plasma samples were considered anti-oocyte antibody-positive if fluorescence was greater than the background fluorescence found in the negative control. 


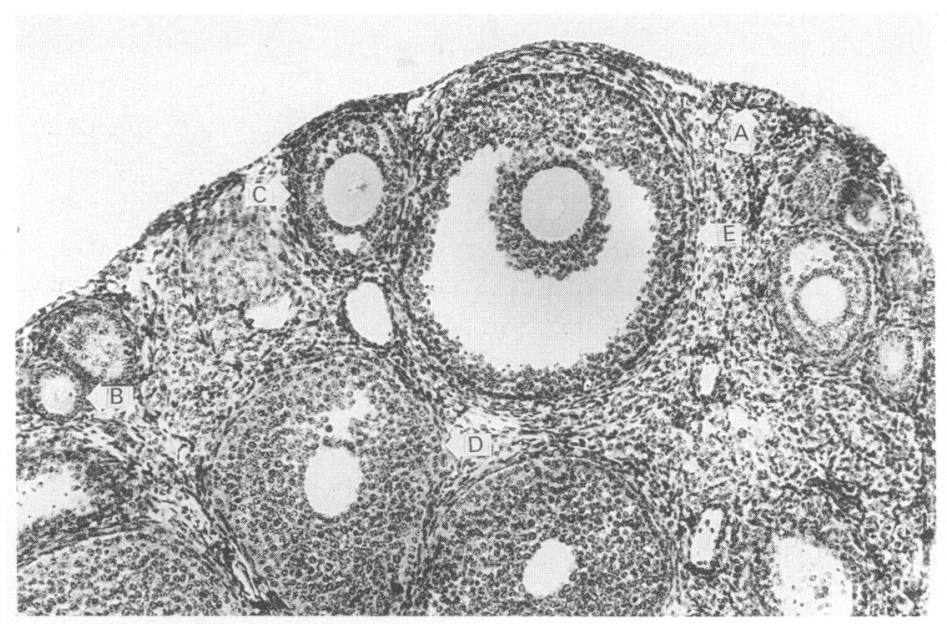

\begin{tabular}{|c|c|c|c|c|}
\hline Reference & $\begin{array}{l}\text { Follicle } \\
\text { type }\end{array}$ & Oocyte size & Granulosa cell no. & Morphology range \\
\hline A & Primordial & $<20 \mu \mathrm{m}$ & $<20$ & $\begin{array}{l}\text { Non-growing oocyte with few } \\
\text { attached cells or single ring of cells }\end{array}$ \\
\hline B & Preantral & $>20-70 \mu \mathrm{m}$ & $20-200$ & $\begin{array}{l}\text { Growing oocyte with single layer or } \\
\text { multilayer of cells; no follicular } \\
\text { fluid accumulation }\end{array}$ \\
\hline C & $\begin{array}{l}\text { Precocious } \\
\text { antral }\end{array}$ & $>20-70 \mu \mathrm{m}$ & $60-200$ & $\begin{array}{l}\text { Growing oocyte with multilayer of } \\
\text { cells; premature follicular fluid } \\
\text { accumulation }\end{array}$ \\
\hline D & Antral & $70 \mu \mathrm{m}$ & $>200$ & $\begin{array}{l}\text { Large oocyte with multilayer of cells } \\
\text { and initial follicular fluid } \\
\text { accumulation or early antral } \\
\text { formation }\end{array}$ \\
\hline$E$ & Pre-Graafian & $70 \mu \mathrm{m}$ & $>600$ & $\begin{array}{l}\text { Mature oocyte with multilayer of } \\
\text { cells and antral formation with } \\
\text { cumulus oophorus or cumulus stalk }\end{array}$ \\
\hline
\end{tabular}

Fig. 1. Follicle classification system based upon oocyte size, granulosa cell number, and follicular morphology (modified from Pederson \& Peters, 1968).

\section{Results}

\section{Ovarian morphology}

We could not detect any significant differences in morphology between intact and shamthymectomized mice at any age observed. Ovaries from intact and thymectomized infant mice at 5 and 10 days of age contained large numbers of primordial and growing follicles, with very few atretic follicles (Fig. 2a,b; Fig. 3a). Precocious antral follicles, normally prevalent in the prepubertal mouse ovary (Peters \& Braathen, 1973), were seen in ovaries from intact and thymectomized mice from 10 through 30 days of age (Fig. 2a-e, Fig. 3a,b).

Visible differences between intact and thymectomized mice were first observed at about 20 days of age. Ovaries from thymectomized mice at this age had fewer small, growing follicles (preantral follicles). At 20 days of age, antral follicles in ovaries from thymectomized mice were larger (Fig. 2c). These large antral follicles had more granulosa cells with a resultant increase in follicular diameter, but much smaller antral cavities.

By 25 days of age there was a further decrease in growing follicles from ovaries of thymectomized mice (Fig. 2d; Fig. 3b). This was accompanied by areas of structural disorganization. At this age, 


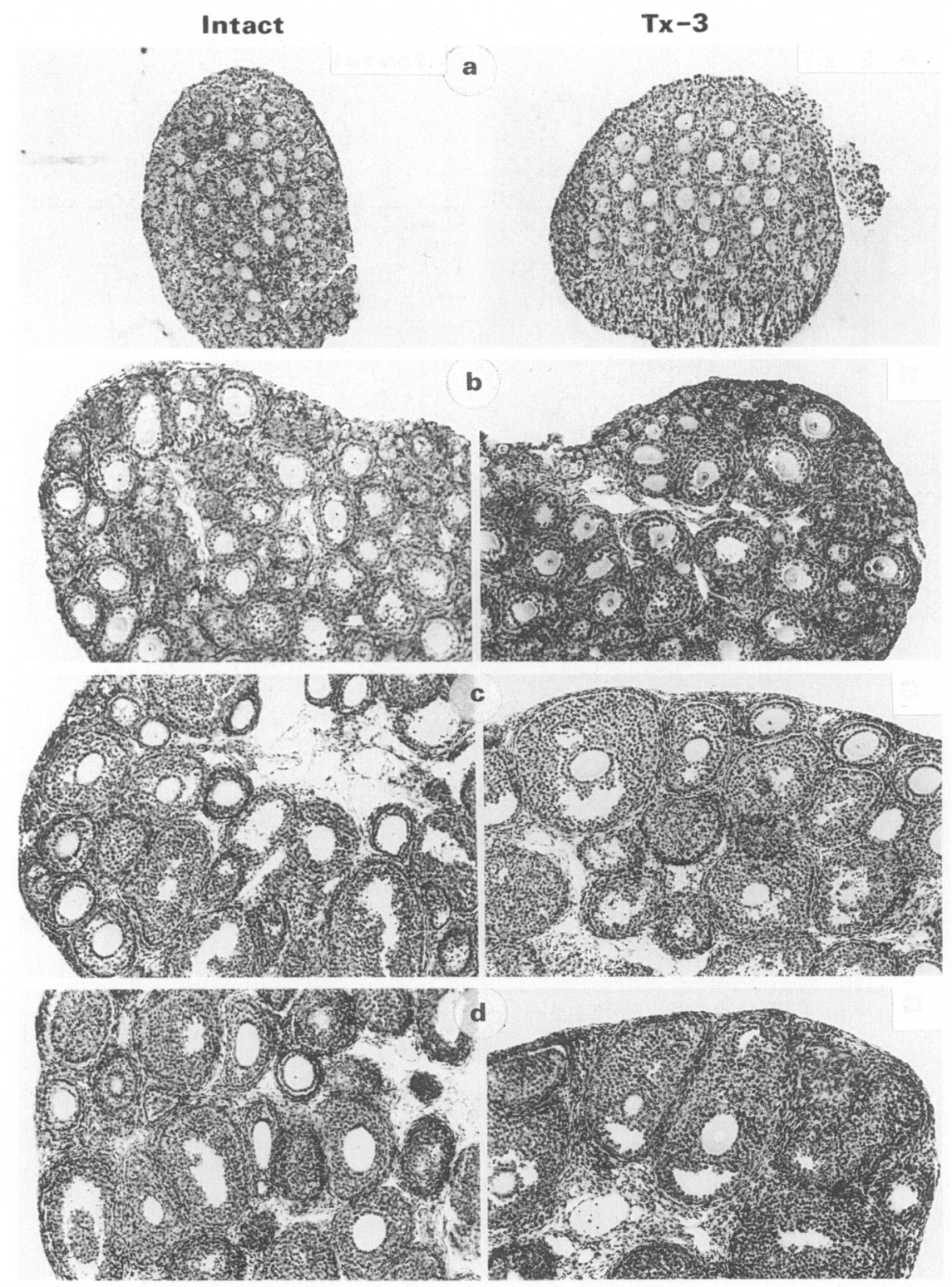

Fig. 2 (a-d)

the antral follicles continued to be larger in ovaries from thymectomized mice. Small darkly-stained cells were also observed within and around medium and large-sized growing follicles. These cells appeared to be morphologically different from the pycnotic granulosa cells generally seen in atretic follicles. Previous studies have identified these cells as lymphocytes (Sakakura et al., 1979).

By 30 days of age there was a marked decrease of all follicle populations in thymectomized mice, and most of the remaining follicles were visibly degenerating (Fig. 2e). At this age, the oocytes of most 'growing' follicles were noticeably degenerating and contained pycnotic granulosa cells. Growing follicles with intact oocytes were rarely seen, although a few large antral follicles appeared intact. The above-mentioned darkly-stained cells were dispersed throughout the ovary by this age. 

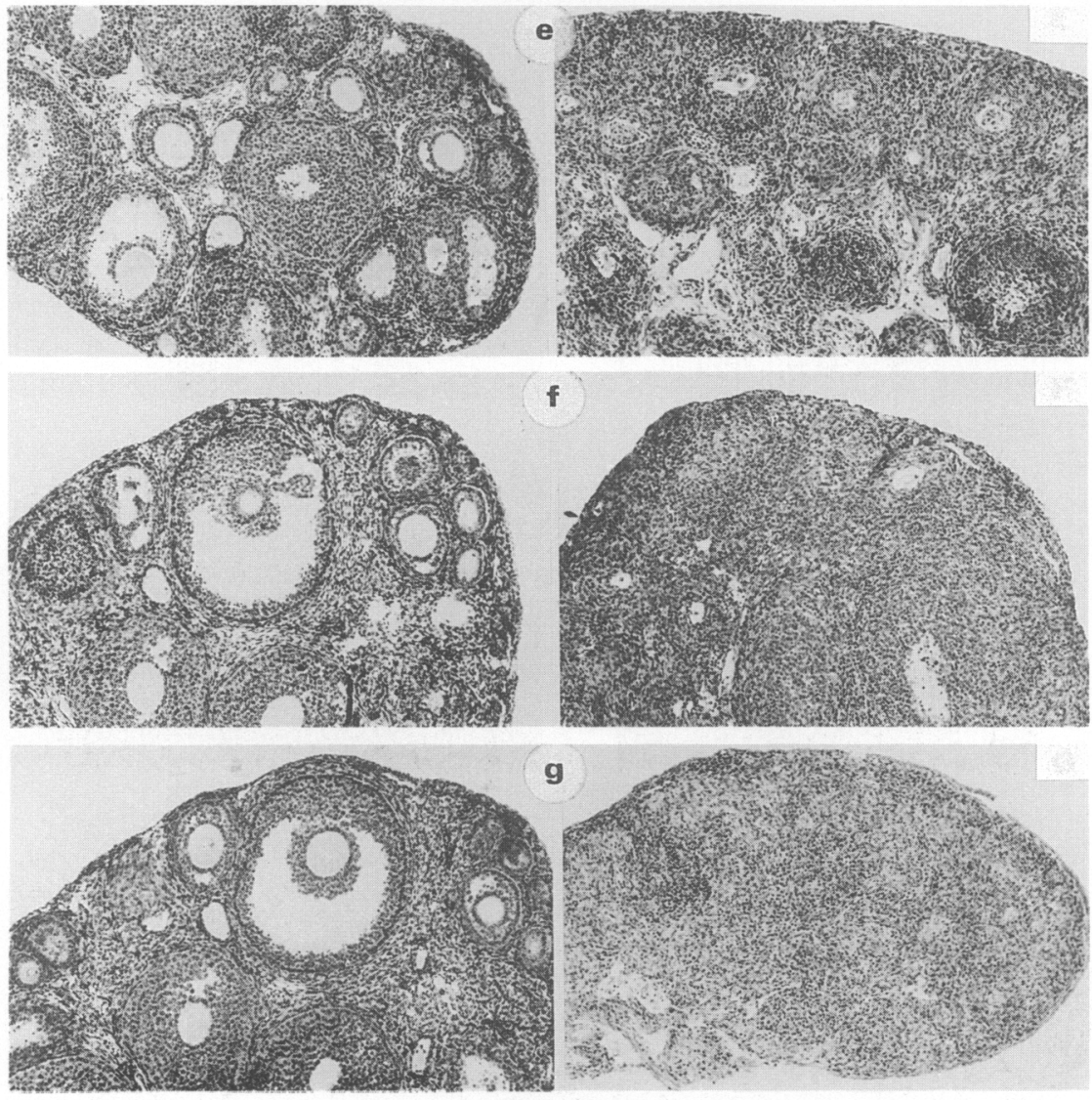

Fig. 2 (e-g)

Fig. 2. Ovarian morphology of mice thymectomized on Day $3(\mathrm{Tx}-3)$ compared to intact mice at various ages. (a) No visible difference (5 days). (b) No visible difference (10 days). (c) Fewer preantral follicles and antral follicles appear larger in Tx-3 mice (20 days). (d) Further reduction of preantral follicles and antral follicles continue to appear larger but have poorly developed antrum in Tx-3 mice (25 days). (e) Marked disruption of follicular integrity with many follicles present without oocytes (30 days). (f) Further follicular destruction ( 35 days). (g) Complete follicular destruction and lack of structural organization (40 days). Photographed at $\times 100$.

At 35 days of age very little follicular structure could be identified in ovaries from thymectomized mice (Fig. 2f). Remnants of oocytes (and possibly zona pellucida) were occasionally seen throughout the ovary. Individual cells were not easily distinguishable as the tissue took on a more homogeneous appearance. A few primordial follicles were still seen and were randomly dispersed throughout the tissue.

By 40 days of age most ovaries from thymectomized mice (80-90\%) were atrophied and completely dysgenic with little apparent structural organization (Figs $2 \mathrm{~g} \& 3 \mathrm{c}$ ). The tissue appeared completely homogeneous with even vascular tissue difficult to detect. The majority of cells looked very similar to fibroblasts and/or thecal cells.

\section{Ovarian weight}

Ovaries from intact and thymectomized mice increased in weight from 5 to 25 days of age (Fig. 4). Ovaries from thymectomized mice were significantly heavier at 15 and 20 days of age than those 

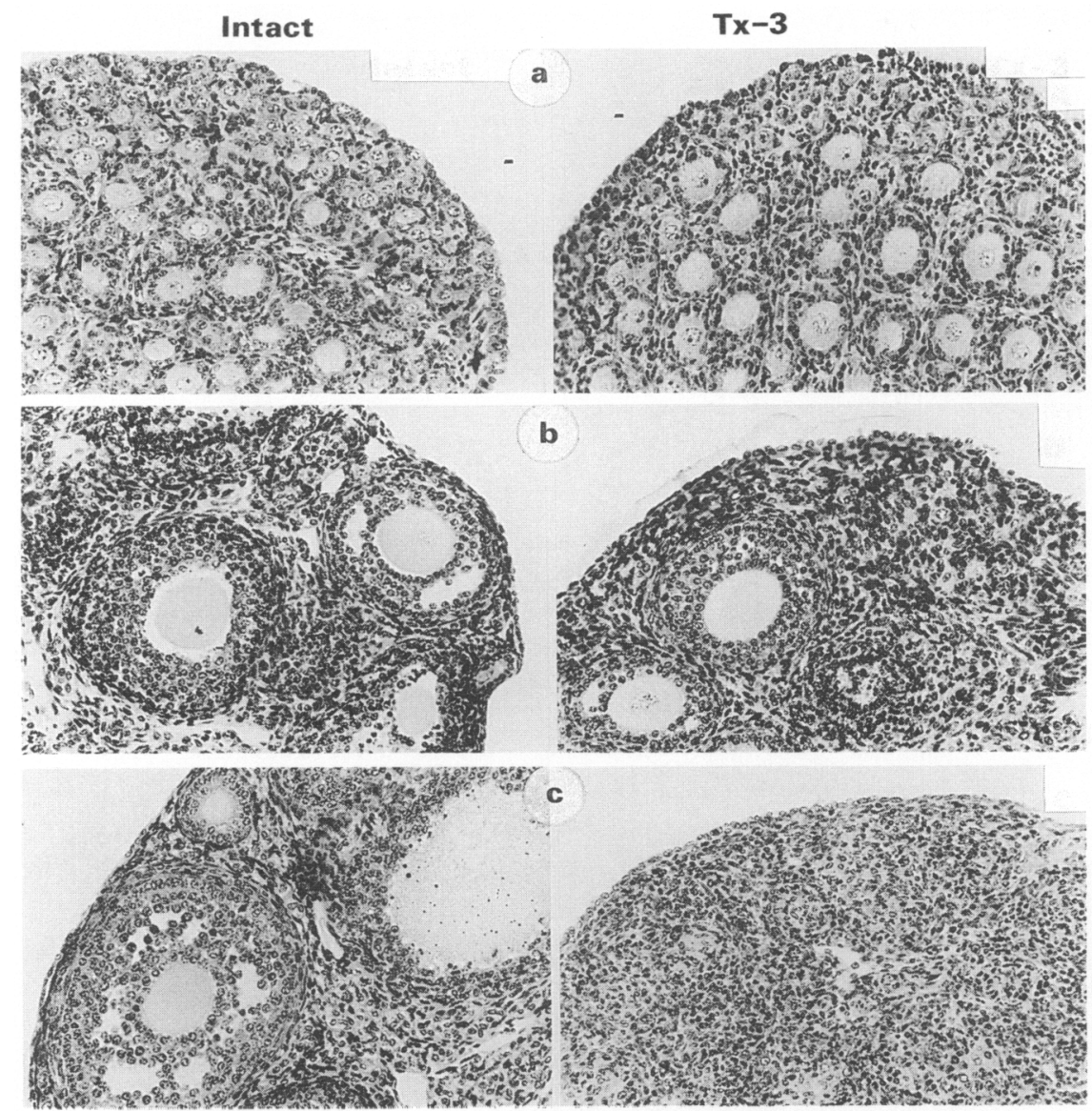

Fig. 3. Higher magnification of ovarian morphology of mice thymectomized on Day 3 (Tx-3) compared to intact mice at various ages: (a) 5 days; (b) 25 days; (c) 40 days - note the absence of follicles or other structural organization in the section from a Tx-3 mouse. Photographed at $\times 200$.

from intact mice, but by 40 days of age the ovaries from intact mice were significantly heavier. At 40 days of age, ovarian weights in sham-thymectomized mice were significantly less than those of intact mice but greater than those from thymectomized animals $(P<0.01)$.

\section{Quantitative analyses}

Total follicles. In intact and thymectomized animals there was a marked decline in the total follicle number between 5 and 40 days of age (Fig. 5). The total follicle number, however, was consistently and significantly lower in ovaries from thymectomized mice at 10 through 40 days of age. To determine whether there was any correlation between total follicle number and chronological age, data from intact and thymectomized mice were subjected to linear regression analysis. There was a linear relationship with a correlation coefficient of -0.99 for intact mice and -0.98 for thymectomized mice. The calculated slopes of -0.03 for thymectomized mice and -0.01 for intact mice reveal a greater rate of decline of the total follicle number in ovaries from thymectomized mice.

Growing follicles. The number of growing follicles (all follicle populations minus the primordial) at 5 days of age was significantly lower in thymectomized mice than in intact mice (Fig. 6). Although these numbers tended to be lower in ovaries from thymectomized mice at 10 and 15 days 


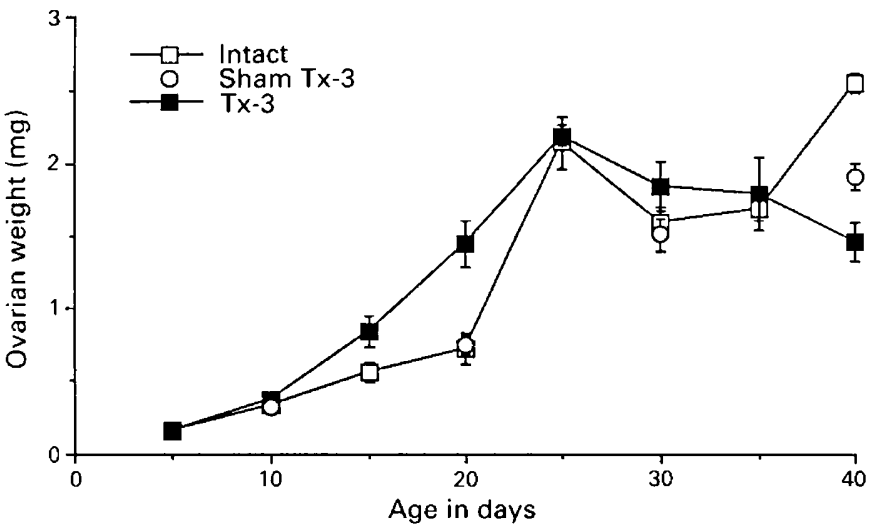

Fig. 4. Ovarian weights in intact mice and mice thymectomized (Tx-3) and shamthymectomized (sham-Tx-3) on Day 3 from 5 to 40 days of age. Each point represents the mean \pm s.e.m. (of the averages of right and left ovaries) of not less than 8 animals. Standard error bars that do not overlap indicate significant differences at $P<0.05$. (At some points the open symbols have been obliterated by the darker symbols for Tx-3 animals; in some cases error bars may be smaller than the width of the symbol and are therefore not evident on the graph.)

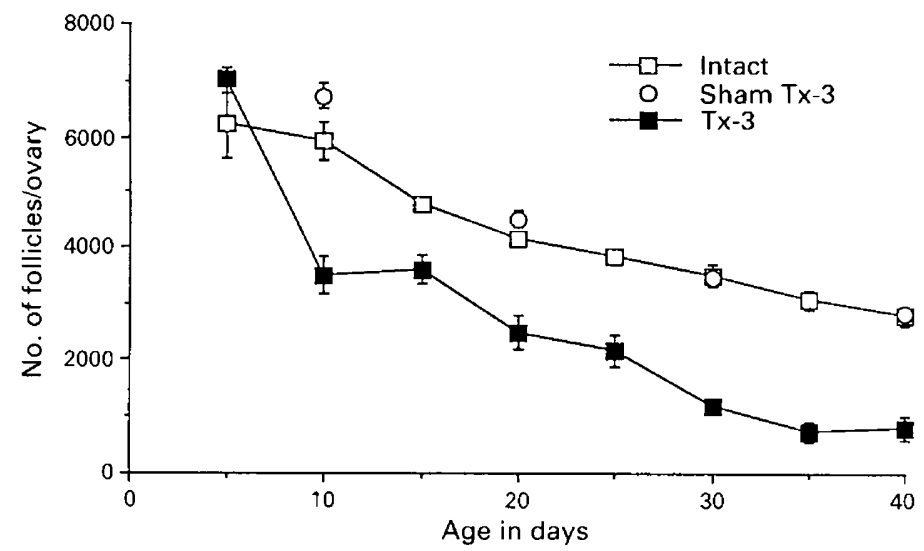

Fig. 5. Total follicle numbers in intact mice and mice thymectomized (Tx-3) and shamthymectomized (sham Tx-3) on Day 3 from 5 to 40 days of age. Each point represents mean \pm s.e.m. (of the averages of right and left ovaries) of not less than 8 animals. Standard error bars that do not overlap indicate significant differences at $P<0.05$. (In some cases error bars may be smaller than the width of the symbol and are therefore not evident on the graph.)

of age, there was not a statistical difference. The number of growing follicles in intact mice reached a peak at about 20 days of age. No corresponding follicle growth peak was seen in ovaries from thymectomized mice. The number of growing follicles was significantly lower in thymectomized mice at 20 days of age. The number of growing follicles in sham-thymectomized animals was also significantly lower $(P<0.01)$ than in intact mice at 20 and 30 days of age, but was significantly greater than in thymectomized animals $(P<0.006)$ at these ages. Through 40 days of age, the numbers of growing follicles in thymectomized mice continued to remain significantly lower than those found in intact mice.

Primordial follicles. There was a dramatic decrease in the primordial follicle population by 10 days of age in ovaries from thymectomized mice (Fig. 7). While the primordial follicle population 


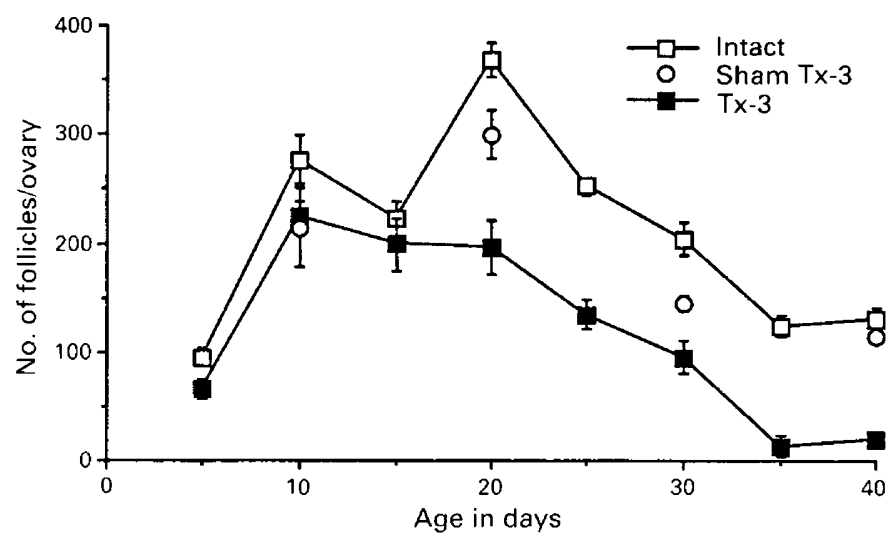

Fig. 6. Growing follicle numbers (sum of preantral, precocious antral, antral and pre-Graafian follicle numbers) in intact mice and mice thymectomized (Tx-3) and sham-thymectomized (sham-Tx-3) on Day 3 from 5 to 40 days of age. Standard error bars that do not overlap indicate significant differences at $P<0.05$. (In some cases error bars may be smaller than the width of the symbol and are therefore not evident on the graph.)

of intact mice also underwent a prepubertal decline, the rate of decline was accelerated in ovaries from thymectomized mice. Since the primordial follicle population accounts for a large proportion of the total follicles, the age-related patterns of decline in this follicle population are similar to those found for the 'total follicle' population. There was a significantly greater number of primordial follicles in sham-thymectomized animals than in intact animals at 10 days of age $(P<0 \cdot 01)$.

Preantral and precocious antral follicles. No significant differences in preantral follicle numbers were found between intact and thymectomized mice until 20 days of age. At this time a growth peak normally found in intact mice was absent in thymectomized mice. As shown in Fig. 7, preantral follicle numbers in thymectomized mice were significantly lower at this age. Preantral follicles continued to decrease in ovaries from thymectomized mice and remained significantly lower through 40 days of age. Preantral follicle numbers in sham-thymectomized animals were significantly lower than in intact animals $(P<0.004)$ but significantly greater than in thymectomized animals $(P<0.001)$ at 20 days of age. There was very little difference in the numbers of precocious antral follicles between ovaries from intact and thymectomized mice until 30 days of age when follicle numbers were significantly lower in thymectomized mice through 40 days of age (Fig. 7).

Antral follicles. Antral follicles were not seen in ovaries from intact, thymectomized or shamthymectomized mice until 20 days of age. From 20 through 40 days of age antral follicles were significantly lower in ovaries from thymectomized mice (Fig. 7).

Pre-Graafian follicles. Pre-Graafian follicles were found in the ovaries from intact mice at 30 days of age, but were not found in thymectomized animals at any age (Fig. 7).

\section{Immunofluorescence}

Anti-oocyte antibodies were found in serum from 30-, 40- and 60-, but not 10- or 20-day-old thymectomized female mice. Serum was anti-oocyte antibody-positive in $84 \%$ of the 60 -day-old, $66 \%$ of the 40 -day-old and $56 \%$ of the 30 -day-old thymectomized animals. Anti-oocyte antibodies were specific for the oocytes of all 5 types of follicles (primordial, preantral, precocious antral, antral and pre-Graafian) as tested against ovaries from intact animals (Fig. 8a-d); this was true for all anti-oocyte antibody-positive sera and for ovaries from intact animals of all three age groups $(10,20$ and 30 days).

The area of specificity for the anti-oocyte antibodies appeared to be the cytoplasm of the oocytes. Neither the zona pellucida nor other ovarian cells were targets for anti-oocyte antibodies. 


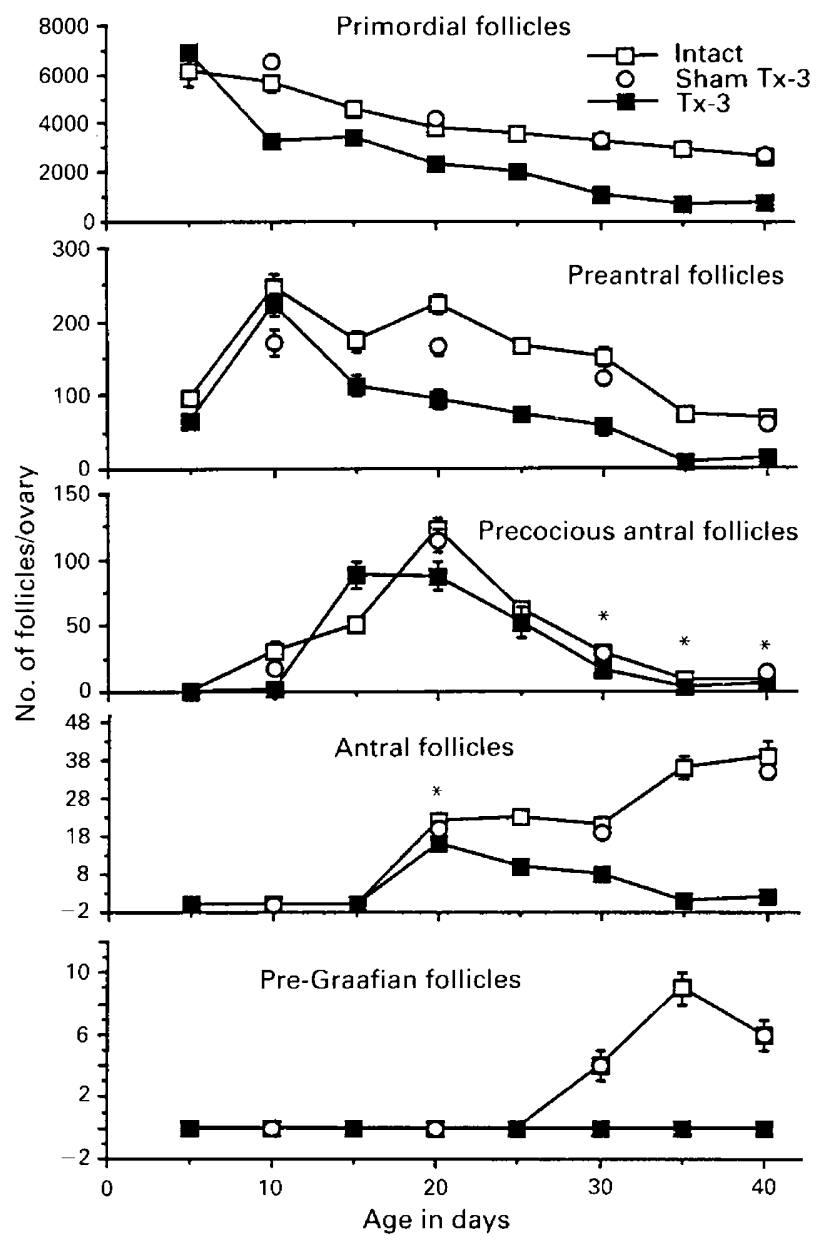

Fig. 7. Primordial, preantral, precocious antral, antral, and pre-Graafian follicle numbers in intact mice and mice thymectomized (Tx-3) and sham-thymectomized (sham-Tx-3) on Day 3 from 5 to 40 days of age. Standard error bars that do not overlap indicate significant differences at $P<0.05$. $^{*}$ indicates $P<0.05$ even though s.e.m. bars overlap. (At some points the open symbols have been obliterated by the darker symbols for Tx-3 animals; in some cases error bars may be smaller than the width of the symbol and are therefore not evident on the graph.)

The specificity of anti-oocyte antibodies to the cytoplasm was most obvious in the primordial follicles and in these fluorescence appeared as a distinctive halo (the cytoplasm) which encircled the relatively large nucleus of the primordial oocyte (Fig. 8c, d). As stated previously, ovarian antigens were present in ovaries from intact animals in all three age groups tested, and similar patterns of oocyte fluorescence were seen at each age.

\section{Discussion}

Neonatal thymectomy resulted in severe losses in the primordial follicle population in prepubertal B6A mice. In intact mice there is an extensive loss of small, non-growing follicles shortly after birth (Peters, 1969). This is normal. This loss is accelerated in thymectomized mice before 10 days of age. The thymectomy-induced decline in the primordial follicle population that we see has not been reported in two previous studies. Neither Sakakura et al. (1979) nor Miyake et al. (1987) found a 

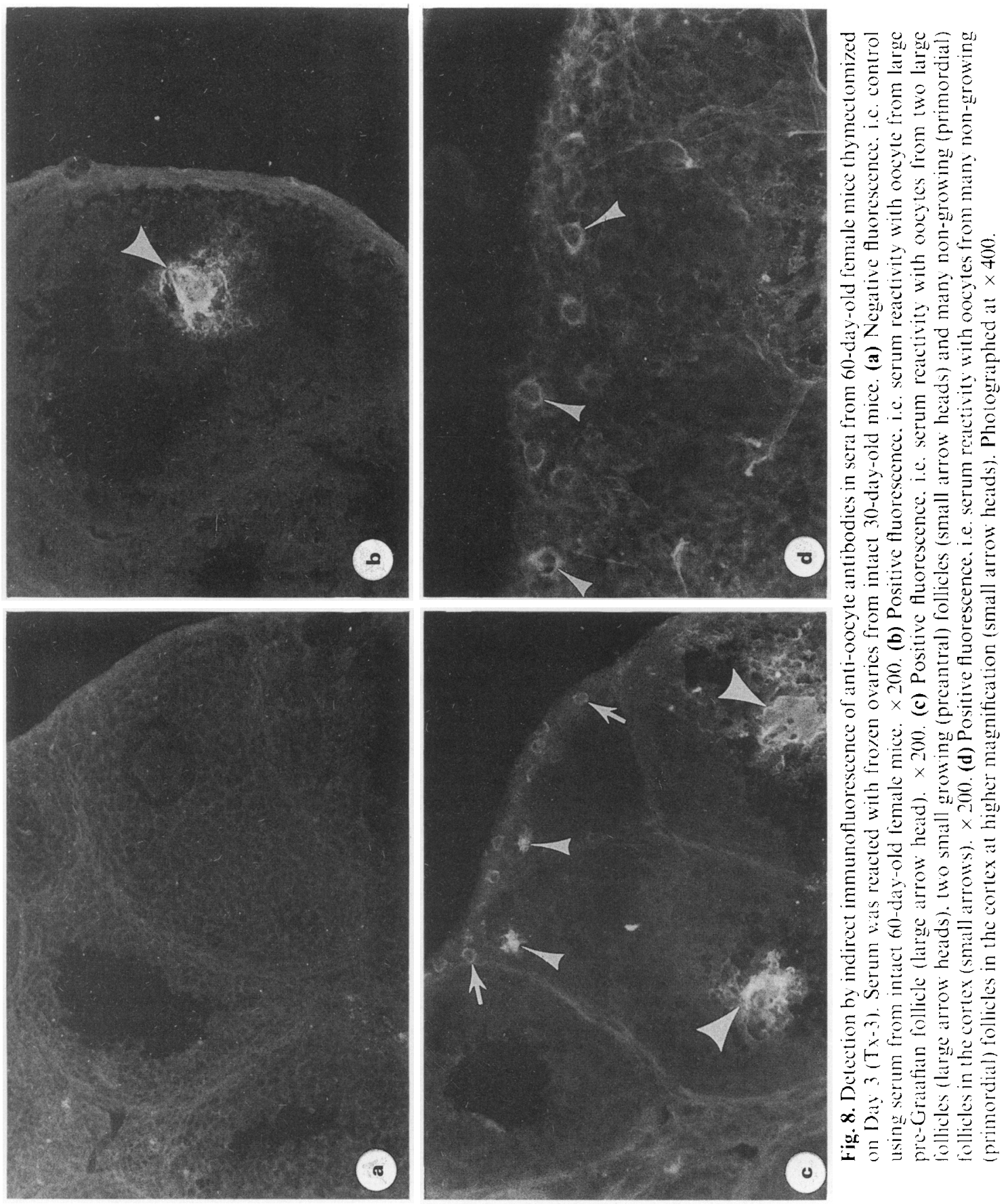
decrease in oocyte or follicle number until about 30 days of age in B6A mice. The difference between studies may be the result of slightly different experimental procedures, i.e. differences in the exact timing of the surgical procedure on Day 3 of age or in the histological or screening techniques. These previous studies also found that anti-oocyte antibodies from thymectomized animals were exclusively against the oocytes within growing follicles, whereas in our study the antioocyte antibodies from thymectomized animals were against the oocytes of follicles of all types, including primordial.

Additional reports in the literature indicate that there may be a variety of responses to thymectomy. Lintern-Moore \& Norbaek-Sorensen (1976) thymectomized female Bagg albino mice $48 \mathrm{~h}$ after birth and found that follicle numbers decreased only after 12 weeks of age. In a study using thymectomized rats, Lintern-Moore (1977) found an early decline in follicles and a particularly sharp decrease in primordial follicles between 10 and 21 days of age. Healy et al. (1985) reported reduced numbers of germ cells in fetal primates that were thymectomized in utero. It appears that the effect of neonatal thymectomy is species- as well as strain-related, and is dependent upon a variety of experimental constraints, including the timing of surgery.

Infertility in women has often been associated with circulating anti-ovarian antibodies (Coulam, 1983). The presence of analogous antibodies in thymectomized mice suggests that this may be the mechanism for the oocyte destruction. However, the temporal relationship between the decrease in primordial follicles and the initial identification of circulating anti-oocyte antibodies (10 days vs 30 days of age) suggests that this may not be a simple cause-and-effect relationship. And in view of the fact that the immune system in mice is still relatively immature at 10 days of age, we are not convinced that the lower numbers of primordial follicles seen in thymectomized mice at this age were the direct result of an autoimmune response.

There is little in the literature concerning the physiology of the primordial follicle population. It is known that they can be destroyed by such invasive treatments as irradiation, neonatal testosterone injection, and chemical carcinogens (see Peters \& Levy, 1964; Gondos, 1978). The process of primordial follicle elimination normally occurs via extrusion through the surface epithelium or lysis and subsequent phagocytosis. Baker (1982) suggests that small follicle (primordial) degeneration may result from genetic defects, errors in metabolism, or may possibly be due to a shortage of nutrients resulting from incompetent follicular cells and/or a paucity of blood supply. From the results of the present study, we speculate that thymectomy may have accelerated the existing process of primordial follicle degeneration by either influencing the ovarian blood supply, metabolism, or follicular cell function. Or, alternatively, thymectomy may have interrupted or disturbed the process of folliculogenesis. Previous studies have shown that folliculogenesis (defined as the initial formation of the follicle from a naked oocyte) begins at about 2 days of age in several strains of mice (Borum, 1961; Peters, 1969). It is likely that oocytes that have not yet undergone folliculogenesis are still present at 5 days of age in thymectomized and intact mice. Since oocytes that are not enclosed in a follicle eventually degenerate (see Peters \& McNatty, 1980), the decline in primordial follicles seen by 10 days of age in thymectomized mice may be due to disruption in follicle formation that results in oocyte destruction.

There were fewer growing follicles (includes preantral, precocious antral, antral and preGraafian follicles) in thymectomized mice from 20 to 40 days of age. The data reported by Krarup et al. (1969) indicate that the rate of recruitment into the growing follicle population in a normal animal at any given time is dependent upon the size of the non-growing follicle pool. We have calculated the ratio of growing to primordial follicles in ovaries from intact and thymectomized mice. There was no difference in this ratio in mice from 15 to 35 days of age. Therefore, the lower number of growing follicles in thymectomized mice seen during these ages may be due to the smaller pool of primordial follicles that remains after 10 days of age. This suggests that the initial damage to the ovary was done before 10 days.

Alternatively, a lowered endocrine response may be involved in the lack of follicular growth in thymectomized mice between 15 and 25 days of age. Circulating concentrations in FSH, LH and 
GH are lower in prepubertal thymectomized mice than in intact mice (Dullaart et al., 1975; Michael et al., 1980). Contrary to a widely held view, a recent review of the literature suggests that both follicular recruitment and preantral follicle growth are gonadotrophin-dependent (Greenwald \& Terranova, 1988). For example, athymic, hypogonadal and hypophysectomized mice all have low concentrations of pituitary hormones, and in turn have fewer growing follicles (Lintern-Moore \& Pantelouris, 1976; Rebar et al., 1981; Halpin et al., 1986). Paradoxically, at these ages (15 and 20 days of age) ovaries from thymectomized mice are significantly heavier than those from intact mice. This weight difference is transient and by 40 days of age ovaries from thymectomized mice weigh significantly less. During this period, antral follicles found in thymectomized mice appear to be larger (although there are fewer of them) than those found in intact mice and this may account for the greater weight. A possible mechanism(s) for this phenomenon is presently not known.

We can find no evidence to suggest that an autoimmune reaction was responsible for the decreased number of growing follicles found at 20 days of age in the thymectomized mouse. There were no lymphocytes in the ovary or circulating anti-oocyte antibodies until 25 and 30 days of age, respectively, even though our immunofluorescence studies indicated that antigen(s) was present in the ovary at 20 days of age. Still, it may be that anti-oocyte antibodies at these ages and earlier were either at levels too low to detect with immunofluorescence or that the anti-oocyte antibodies were in the form of IgMs (at later ages the anti-oocyte antibodies are of the IgG type). Additionally, qualitatively, there did not appear to be an increase in the number of atretic follicles. There is no evidence, therefore, to indicate that the lower number of growing follicles at this age ( 20 days of age) is due to an autoimmune reaction. There is evidence that suggests that the follicles were simply not recruited into the growing follicle population in the same numbers as those found in intact mice.

By 30 days of age, however, follicular atresia was accelerated in thymectomized mice. Oophoritis and follicle degeneration were widespread and affected all follicle types. Lymphocyte infiltration of the ovary and the presence of anti-oocyte antibodies in serum at 30 days of age in thymectomized mice seemed to correlate with the acceleration of follicular atresia at this age but not earlier. And by 40 days of age, a representative ovary from a thymectomized B6A mouse had the following characteristics: (1) few primordial follicles; (2) no healthy follicles or corpora lutea; (3) no discernible structural organization; and (4) a large portion of the ovary containing tissue that appeared to be homogeneous (i.e. all cell types appeared to be the same).

Thymectomy between 2 and 4 days of age in the B6A mouse influences the ovary in two quantifable and possibly interrelated ways. The first involves changes in the numbers of specific follicle populations before 30 days of age. We speculate that the immune system may not have been involved at this time, whereas we cannot rule out the endocrine function of the thymus gland. The involvement of the latter has been suggested by recent studies of the thymus in which it has been shown that thymic peptides/hormones have other activities in addition to their immune function. These activities include stimulation of release of luteinizing hormone-releasing factor (LRF), adrenocorticotrophic hormone $(\mathrm{ACTH}), \beta$-endorphin, cortisol, prolactin and growth hormone (GH) (see Healy et al., 1983; Rebar et al., 1983; Spangelo et al., 1987). Therefore, it is possible that removal of the endocrine thymus at a critical age may have directly or indirectly influenced the primordial and growing follicle populations through an endocrine mechanism. The second effect of thymectomy results in a tissue-specific autoimmune response. The autoimmune response may be related to the timing of development in both the immune and reproductive systems. Folliculogenesis and initiation of follicular growth occur at about the same time as thymocyte (immature $\mathrm{T}$ cell) differentiation, peripheralization, and migration (i.e. during the first week of life in mice (Brambell, 1927; Peters, 1969; see Clark, 1980)). Sakaguchi et al. (1982a, b) found that a specific population of T cells (defined by the Lyt I + Qa-Ia- surface markers) taken from intact mice prevented ovarian dysgenesis in thymectomized mice. The thymus is a primary immune organ which is responsible for 'self' education of $\mathrm{T}$ lymphocytes. These experiments therefore suggest that the thymus may have been extirpated before a T-cell subpopulation either was capacitated to the oocyte-specific antigen 
by exposure to the appropriate thymic environment or had the chance to migrate to peripheral lymphoid organs. This might explain the autoimmune reaction to antigens found in oocytes from growing follicles. Growing follicles are not yet present in the 3-day-old mouse ovary (Pedersen, 1969) and the immune system may not have been exposed and, therefore, may not have developed tolerance to this self-antigen(s) (oocyte-specific). The presence of anti-oocyte antibodies against primordial oocytes is more difficult to explain since primordial follicles are already present at 3 days of age. It is possible that the excessive antigen load 'seen' by the immune system, which results from the accelerated atresia of primordial follicles found in thymectomized animals between 5 and 10 days of age, may override the anti-self suppression normally found in intact animals and thereby induce an autoimmune response to the primordial oocyte. Studies are presently underway in our laboratory that are designed to: (1) clarify further the role that the thymus plays in the hypothalamic-pituitary-ovarian-thymic axis; and (2) identify the specific components of the oocyte which are antigenic in this model.

We thank Mary Ann Pawlikowski for excellent technical assistance and Dr John Chapman for critical review of the manuscript. Supported in part by a grant from the National Institutes of Health, USA (CA-34344).

\section{References}

Baker, T.G. (1982) Oogenesis and ovulation. In Reproduction in Mammals, Book 1: Germ Cells and Fertilization, pp. 14-45. Eds C. R. Austin \& R. V. Short. University Press, Cambridge.

Borum, K. (1961) Oogenesis in the mouse. A study of the meiotic prophase. Expl Cell Res. 24, 495-507.

Brambell, F.W.R. (1927) The development and morphology of the gonads of the mouse. I. The morphogenesis of the indifferent gonad and of the ovary. Proc. R. Soc. B 101, 351-409.

Clark, W.R.(1980) Structure of the immune system. In The Experimental Foundation of Modern Immunology, pp. 10-27. John Wiley and Sons, Inc., New York.

Coulam, C.B. (1983) Autoimmune ovarian failure. In Seminars in Reproductive Endocrinology, pp. 161167. Ed. L. Speroff. Thieme-Stratton Inc., New York.

Dullaart, J., Kent, J. \& Ryle, M. (1975) Serum gonadotropin concentrations in infant female mice. $J$. Reprod. Fert. 43, 189-192.

Gondos, B. (1978) Oogonia and oocytes in mammals. In The Vertebrate Ovary, pp. 83-120. Ed. R. E. Jones. Plenum Press, New York.

Greenwald, G.S. \& Terranova, P.F. (1988) Follicular selection and its control. In The Physiology of Reproduction, Vol. I, pp. 387-446. Eds E. Knobil \& J. D. Neill. Raven Press, New York.

Halpin, D.M.G., Jones, A., Fink, G. \& Charlton, H.M. (1986) Postnatal ovarian follicle development in hypogonadal (hpg) and normal mice and associated changes in the hypothalamic-pituitary-ovarian axis. J. Reprod. Fert. 77, 287-296.

Healy, D.L., Hodgen, G.D., Schulte, H.M., Chrousos, G.P., Loriaux, D.L., Hall, N.R. \& Goldstein, A.L. (1983) The thymus-adrenal connection: thymosin has corticotropin-releasing activity in primates. Science, NY 222, 1353.

Healy, D.L., Bacher, J. \& Hodgen, G.D. (1985) Thymic regulation of primate fetal ovarian-adrenal differentiation. Biol. Reprod. 32, 1127-1133.
Kojima, A. \& Prehn, R.T. (1981) Genetic susceptibility to posthymectomy autoimmune diseases in mice. Immunogenetics 14, 15-27.

Krarup, T., Pedersen, T. \& Faber, M. (1969) Regulation of oocyte growth in the mouse ovary. Nature, Lond. 224, $187-188$.

Lintern-Moore, S. (1977) Effect of athymia on the initiation of follicular growth in the rat ovary. Biol. Reprod. 17, 155-161.

Lintern-Moore, S. \& Norbaek-Sorensen, I. (1976) The effect of neonatal thymectomy on follicle numbers in the post-natal mouse ovary. Mech. Aging Develop. 5, 235-239.

Lintern-Moore, S. \& Pantelouris, E.M. (1976) Ovarian development in athymic nude mice. I. The size and composition of the follicle population. Mech. Aging Develop. 4, 385-390.

Michael, S.D. (1983) Interactions of the thymus and the ovary. In Factors Regulating Ovarian Function, pp. 445-464. Eds G. S. Greenwald \& P. F. Terranova. Raven Press, New York.

Michael, S.D., Taguchi, O. \& Nishizuka, Y. (1980) Effect of neonatal thymectomy on ovarian development and plasma $\mathrm{LH}, \mathrm{FSH}, \mathrm{GH}$ and $\mathrm{Prl}$ in the mouse. Biol. Reprod. 22, 343-350.

Miyake, T., Taguchi, O., Ikeda, H., Sato, Y., Takeuchi, S. \& Nishizuka, Y. (1987) Acute oocytes loss in experimental autoimmune oophoritis as a possible model of premature ovarian failure. Am. J. Obstet. Gynecol. 158, 186-192.

Nishizuka, Y. \& Sakakura, T. (1969) Thymus and reproduction: sex-linked dysgenesia of the gonad after neonatal thymectomy in mice. Science, $N Y$ 166, $753-755$.

Nishizuka, Y. \& Sakakura, T. (1971) Ovarian dysgenesis induced by neonatal thymectomy in the mouse. Endocrinology 89, 886-893.

Pedersen, T. (1969) Follicle growth in the immature mouse ovary. Acta endocr., Copenh. 62, 117-132. 
Pedersen, T. \& Peters, H. (1968) A proposal for classification of follicles in the mouse ovary. $J$. Reprod. Fert. 17, 555-557.

Peters, H. (1969) The development of the mouse ovary from birth to maturity. Acta endocr., Copenh. 62, 98-116.

Peters, H. \& Braathen, B. (1973) The effect of unilateral ovariectomy in the neonatal mouse on follicular development. J. Endocr. 56, 85-89.

Peters, H. \& Levy, E. (1964) Effect of irradiation in infancy in the mouse ovary. J. Reprod. Fert. 7, 37-45.

Peters, H. \& McNatty, K.P. (1980) Atresia. In The Ovary, pp. 98-106. University of California Press, Berkeley.

Rebar, R.W., Morandini, I.C., Erickson, G.F. \& Petze, J.E. (1981) The hormonal basis of reproductive defects in athymic mice: diminished gonadotropin concentrations in prepubertal females. Endocrinology $108,120-126$.

Rebar, R.W., Miyake, A., Erickson, G.F., Low, T.K.L. \& Goldstein, A.L. (1983) The influence of the thymus gland on reproductive function. A hypothalamic site of action. In Factors Regulating Ovarian Function, pp. 465 471. Eds G. S. Greenwald \& P. F. Terranova. Raven Press, New York.

Sakaguchi, S., Takahashi, T. \& Nishizuka, Y. (1982a) Study on cellular events in postthymectomy immune oophoritis in mice. I. Requirement of Lyt-1 effector cells for oocyte damage after adoptive transfer. $J$. exp. Med. 156, 1565-1576.

Sakaguchi, S., Takahashi, T. \& Nishizuka, Y. (1982b) Study on cellular events in postthymectomy autoimmune oophoritis in mice. II. Requirement of Lyt-1 cells in normal female mice for the prevention of oophoritis. J. exp. Med. 156, 1577.-1586.

Sakakura, T., Taguchi, O., Kojima, A. \& Nishizuka, Y. (1979) Rapid oocyte death prior to and at puberty in neonatally thymectomized mice. In Ovarian Follicular and Corpus Luteum Function, pp. 315-320. Eds C. P. Channing, J. Marsh \& W. A. Sadler. Plenum Press, New York.

Spangelo, B. L., Judd, A. M., Ross, P. C., Logun, I. S., Jarvis, W. D., Badamehian, M., Goldstein, A. L. \& MacLeod, R. M. (1987) Thymosin fraction 5 stimulates prolactin and growth hormone release from anterior pituitary cells in vitro. Endocrinology 121, 2035-2043.

Taguchi, O., Nishizuka, Y., Sakakura, T. \& Kojima, A. (1980) Autoimmune oophoritis in thymectomized mice: detection of circulating antibodies against oocytes. Clin. exp. Immunol. 40, 540-553.

Received 17 April 1989 